D01: 10.12957/demetra.2016.22426

\title{
A mulher transexual no discurso contemporâneo: um estudo de caso
}

\section{Transsexual women in contemporary discourse: a case study}

\author{
Roberta Siqueira Mocaiber Dieguez' \\ I Escola Nacional de Saúde Pública Sergio Arouca \\ - ENSP/FIOCRUZ. Departamento de Direitos \\ Humanos e Saúde, Curso de pós-graduação \\ Lato Sensu em Gênero, Sexualidade e Direitos \\ Humanos. Rio de Janeiro-RJ, Brasil. \\ Correspondência / Correspondence \\ Roberta Siqueira Mocaiber Dieguez \\ E-mail: robertadieguez@posgrad.ensp.fiocruz.br
}

\section{Resumo}

A transexualidade vem sendo cada vez mais discutida na mídia e em outros meios. No entanto, não se pode tratar de um tema tão amplo sem questionar um dos pilares da sociedade: a diferença entre os sexos. Essa discussão se torna necessária, visto que os sujeitos transexuais contrariam os papéis de gênero preestabelecidos de acordo com o sexo biológico. No presente trabalho, analisou-se o estudo de caso de uma mulher transexual, que consiste numa pessoa que foi designada como homem ao nascer, mas se considera uma mulher. Ao longo da entrevista realizada, que consistiu de 18 perguntas sobre a vivência da transexualidade, foi possível perceber vários aspectos do discurso da entrevistada que apontavam para sua dificuldade de encontrar seu lugar social, pois os sujeitos só se tornam inteligíveis na sociedade quando se identificam com o gênero masculino ou feminino. Além disso, supõe-se que só existem dois gêneros possíveis, e que os mesmos devem seguir padrões pré-definidos. Esses padrões seriam construídos historicamente pelas relações de dominação estabelecidas. A partir dessas concepções, as pessoas transexuais acabam se tornando marginalizadas e patologizadas pelos discursos científicos, o que cria inúmeras dificuldades para que sejam reconhecidas. Através do estudo de caso, foi possível também discutir as representações da feminilidade. Após a realização da entrevista, realizou-se análise de conteúdo, cujos resultados apontaram para uma busca, por parte da entrevistada, de encontrar seu lugar em meio a uma sociedade gendrada e heteronormativa.

Palavras-chave: Sexualidade. Identidade de Gênero. Transexual. Feminilidade. 


\section{Abstract}

Transsexualism has been increasingly discussed in the media and other means. However, one cannot treat such a broad topic without questioning one of the pillars of society: the difference between sexes. This discussion is necessary, since transsexual individuals contradict the roles of predetermined genders according to biological sex. In this paper, we have made an analysis of a case study of a transsexual woman. A transsexual woman is a person who has been designated as male at birth, but considers herself to be a woman. Throughout the interview, which consisted of 18 questions about the experience of transsexualism, various aspects of the interviewee's discourse were revealed. They pointed to the difficulty on finding her place in society, because individuals only become intelligible in society when they identify themselves with either the male or female gender. In addition, it is assumed that there are only two possible genders, and that they should follow predefined standards. These standards are assumed to have been built from historically established relations of domination. Based on these concepts, transsexual people become marginalized and pathologized by scientific discourse, which creates many difficulties for them to be recognized. Based on the case study, we could also discuss the representations of femininity. After the interview, a content analysis was performed and the results pointed to a quest by the interviewee to find her place in the middle of a gendered and heteronormative society.

Key words: Sexuality. Gender Identity. Transsexual. Femininity.

\section{Introdução}

O tema da transexualidade tem sido muito discutido nos últimos anos. Em parte, isso é justificado pelo fato de que os casos têm se tornado cada vez mais evidentes na mídia e no convívio social das pessoas, o que está ligado também aos avanços da medicina em relação a cirurgias e tratamentos hormonais direcionados a esses indivíduos. No entanto, o interesse por tratar deste tema surgiu através da observação de como se dão os discursos sobre esses sujeitos, principalmente nos meios de comunicação, onde se pode observar uma objetificação da mulher transexual.

A leitura de obras como $O$ segundo sexo, da autora francesa Simone de Beauvoir, que já colocava em questão o essencialismo com que se costumava ver o sexo, trouxe à tona o interesse nos estudos de gênero, o que vai muito além dos papéis estabelecidos para o masculino e o feminino. ${ }^{1}$ Tais 
papéis foram descritos por Pierre Bourdieu, em A dominação masculina, como consequência das relações de poder que foram estabelecidas entre homens e mulheres. ${ }^{2}$ Posteriormente, a leitura de textos da filósofa Judith Butler permitiu ampliar o debate, visando a uma desnaturalização e desconstrução do conceito de gênero como é conhecido atualmente. ${ }^{3,4}$

Outro fato atual que estimula o estabelecimento dessas discussões diz respeito aos inúmeros movimentos que têm surgido com o objetivo de despatologizar a transexualidade, que ainda é tida pela psiquiatria como patologia mental, estando descrita no CID-10 como "transexualismo". ${ }^{5}$ No DSM-IV, a categoria é descrita como "transtorno de identidade de gênero" e no DSM-V, com os termos "disforia de gênero". Esses movimentos questionam a patologização e psiquiatrização da transexualidade, que designa o domínio sobre o tema para a psiquiatria. Os movimentos também questionam a normalização binária imposta pela psiquiatria, que considera que só existem duas formas de viver e sentir o mundo, que estão relacionadas aos dois gêneros. ${ }^{6}$

Algumas teorias, no entanto, criaram conceitos importantes, como o núcleo de identidade de gênero, criado pelo psiquiatra e psicanalista Robert Stoller, citado por Arán, que estabelece que o sujeito se define como homem ou mulher no segundo ou terceiro anos de vida. ${ }^{7}$ Para o psicólogo John Money, citado por Perelson, o gênero se sobrepõe ao sexo biológico e a "patologia" dos transexuais encontra-se no sexo biológico, devendo este ser corrigido através de procedimentos médicos. ${ }^{8}$

Na psicanálise, há poucas referências sobre o tema, visto que Freud não falou diretamente dele. Lacan, no entanto, considerou a transexualidade uma psicose, pelo fato de o sujeito negar seu próprio órgão genital e ter de inventá-lo. Muitos psicanalistas posteriores a Lacan consideram essa a melhor definição para o transexual e, por esse motivo, não consideram a cirurgia de transgenitalização um procedimento válido.

Diversas áreas do conhecimento têm tentado explicar o fenômeno da transexualidade. A maioria dos estudos aqui abordados, no entanto, preserva a ideia de uma normalização binária, de que o sexo biológico é determinante para a identidade de gênero, e de que existem somente dois gêneros pré-definidos, que são responsáveis por inúmeras características que devem ser seguidas pelos indivíduos. Os sujeitos só se tornam inteligíveis na sociedade a partir de sua identificação com um gênero, masculino ou feminino. Sendo assim, os transexuais, fugindo a essa lógica do binarismo de gênero, se veem pertencentes a um não lugar social, o que faz com que tarefas simples do dia a dia, como frequentar um banheiro público, se tornem uma dificuldade. Esses sujeitos não se encaixam na lógica dos gêneros, o que faz com que, muitas vezes, busquem realizar intervenções, adequando seus corpos e comportamentos de acordo com o gênero com o qual mais se identificam. É preciso compreender, no entanto, que os gêneros são discursos definidos pelas relações de poder presentes na sociedade. $\mathrm{O}$ discurso normativo que caracteriza os gêneros não 
é capaz de capturar todos os corpos que produz. ${ }^{9}$ Assim, os transexuais, transgêneros e travestis, não se encaixando nesse discurso preestabelecido, tornam-se marginalizados ou patologizados, sendo vistos como seres desviantes.

Embora sejam, em sua maioria, marginalizados, cresce cada vez mais o número de transexuais com ensino superior. Aos poucos, essas pessoas estão se inserindo na sociedade. Pode-se dizer, porém, que a mesma ainda não está preparada para lidar com a ideia de que existem pessoas que não estão de acordo com a diferenciação de gêneros imposta. Com isso, os transexuais enfrentam várias dificuldades no dia a dia, pois vivem num mundo separado entre "coisas de homem" e "coisas de mulher", no qual sentem dificuldade em encontrar seu lugar social. ${ }^{10}$

A dificuldade de se abordar um tema tão amplo se dá pela dificuldade de questionar um saber que foi naturalizado na cultura, que é a diferença entre os sexos. A invocação de uma "natureza" sexuada é responsável pela dificuldade, até mesmo no meio científico, de se pensar os corpos para além do discurso da diferença entre os sexos, que já traz junto a si uma infinidade de conceitos sobre como os gêneros devem se apresentar de acordo com sua "natureza". A feminilidade também pode ser entendida como um discurso, que, por ultrapassar a lógica da primazia do falo, pode se desdobrar em inúmeras possibilidades.

Percebe-se, a partir dos discursos analisados, que as várias áreas do conhecimento que buscam definir o tema da transexualidade tentam designar esse saber para si, gerando várias controvérsias entre os diferentes autores. Torna-se importante, portanto, buscar no discurso da mulher transexual, um saber que é resultado de suas vivências.

Nessa perspectiva, o objetivo do presente trabalho foi escutar esse discurso, comparando-o com as diversas teorias citadas no trabalho e questionando, sobretudo, a imposição de um binarismo de gênero, que acaba por dificultar a compreensão dos corpos daqueles que não se encaixam nessa lógica. Através desses questionamentos, é possível trazer novas possibilidades de pensar esses corpos, contribuindo na criação de novos saberes acerca do tema, visto que o mesmo está longe de ter se esgotado.

\section{Materiais e métodos}

A metodologia deste estudo é de natureza qualitativa, o que consiste na obtenção de dados descritivos sobre o objeto de estudo, em que o pesquisador busca compreender os fenômenos através da perspectiva dos sujeitos da pesquisa. O método utilizado foi um estudo de caso, que, segundo Godoy (1995), caracteriza-se pela análise profunda de um objeto específico. Para o autor, o estudo de caso tem como objetivo aprofundar a compreensão de determinado fenômeno através 
da multiplicidade de dimensões que costumam aparecer. A pesquisa pode ser feita tanto através de casos típicos, quanto de casos excepcionais. ${ }^{11}$

A pesquisa utilizou uma entrevista semiestruturada contendo 18 perguntas sobre a experiência vivida da transexualidade. De acordo com Queiroz, citado por Duarte, a entrevista semiestruturada consiste numa técnica de coleta de dados, através de uma conversação continuada entre entrevistado e pesquisador, em que só interessam ao pesquisador os fatos da vida do entrevistado que tiverem relação direta com a pesquisa. ${ }^{12}$

Utilizou-se como critério para a realização da entrevista a identificação da participante como mulher transexual. Entendem-se por mulheres transexuais aquelas que, tendo passado ou não por uma cirurgia de transgenitalização, nasceram com o sexo biológico masculino, mas identificam-se exclusivamente com o gênero feminino. Na perspectiva da patologização, as mulheres transexuais seriam definidas por pessoas que nasceram com o sexo biológico feminino e passaram por um processo transexualizador para se tornarem homens, ${ }^{13}$ frequentemente chamadas pela sigla FTM, cuja tradução significa "de fêmea para macho". Os transexuais que nasceram com o sexo biológico masculino seriam, portanto, chamados de MTF, cuja tradução significa "de macho para fêmea" e reconhecidos como homens transexuais. ${ }^{14}$ No entanto, para Bento citado por Freire, o que faz com que o sujeito se defina como pertencente a determinado gênero é seu sentimento em relação a sua identidade. ${ }^{13}$ Por esse motivo e em respeito à entrevistada, optou-se por utilizar o gênero feminino em quaisquer referências a ela, visto que a mesma sente-se e apresenta-se como mulher.

Podem-se distinguir dois grupos de transexuais: aqueles que vivem continuamente como mulheres, mas não se submeteram à cirurgia de mudança de sexo; e os transexuais que se submeteram à cirurgia. ${ }^{15}$ Sendo assim, a cirurgia de transgenitalização não constituiu critério para a realização desta pesquisa, visto que não é critério para definir uma mulher transexual. A orientação sexual também não foi critério para realização da pesquisa, visto que a mesma busca compreender a identidade de gênero, o que difere fundamentalmente da orientação sexual.

A busca pelo sujeito da pesquisa se deu através de uma página de uma rede social da internet dedicada a fãs do livro Viagem solitária, que conta a biografia de João W. Nery, um homem transexual, e seu percurso em direção ao seu reconhecimento pela sociedade como homem. Após o contato com o dono da página, o mesmo sugeriu uma mulher transexual que poderia participar da pesquisa e fez-se contato com ela, inicialmente na própria rede social. Após explicar à participante como funcionaria a pesquisa, foi marcado um encontro, onde a entrevista ocorreu.

Os temas abordados foram referentes à experiência vivida pela entrevistada como transexual. Foram abordadas questões sobre possíveis diagnósticos que ela já tivesse recebido, assim como suas perspectivas com relação a eles. Também foi abordada sua relação com o órgão masculino, e com características masculinas que tinha ou que ainda percebia em si mesma. Outra questão abordada dizia respeito à descoberta, por parte da entrevistada, de sua condição transexual, 
referente ao momento em que isso ocorreu e quais foram os elementos principais que a fizeram perceber. O projeto foi submetido e aprovado no comitê de ética dos Institutos Superiores de Ensino (ISECENSA), registrado sob número 798.368.

A participante desta pesquisa assinou um Termo de Consentimento Livre e Esclarecido, autorizando a utilização dos dados coletados. Ela não terá sua identidade divulgada e receberá o codinome de Renata, a fim de preservar sua identidade e segurança. A entrevista foi gravada e posteriormente transcrita para facilitar a análise dos dados.

Após a entrevista, foi feita uma análise de conteúdo, que consiste numa sistematização de uma atitude que conta com elementos variados e dispersos, de forma a objetivar a análise. Esse tipo de análise: "aposta grandemente no rigor do método como forma de não se perder na heterogeneidade de seu objeto."16

\section{Resultados e Discussão}

\section{Reflexões sobre o caso "Renata"}

A feminilidade, ao ultrapassar a lógica da primazia do falo criada por Freud, ${ }^{17}$ pode ser associada com as relações de dominação que regem a sociedade. Essas relações são responsáveis pela construção da diferença entre os sexos, que define que é masculino tudo aquilo que se refere à dominação, ao espaço público e à virilidade, enquanto o feminino se caracteriza pela ideia de ser dominada, pelo espaço privado da casa e pela fragilidade. ${ }^{2}$ Para Beauvoir, a mulher não se define por si mesma, mas somente em relação ao homem. Assim, em todas as sociedades, o homem foi visto como sujeito e a mulher foi representada como o outro, aquilo que difere do homem, o segundo sexo e o ser castrado em relação ao homem, que é o possuidor do falo. ${ }^{1}$

Compreender esse cenário torna-se necessário antes de dar início à análise do caso propriamente dito, visto que as representações dos gêneros masculino e feminino são históricas. O presente trabalho é um estudo de caso de uma mulher transexual e, por isso, é necessário fazer uma breve reflexão sobre o feminino e a diferenciação entre os sexos.

Butler destaca que o corpo é uma construção social e que o gênero seria um significado assumido por um corpo, que só existe em relação a outro significado oposto. ${ }^{3}$ Ou seja, o corpo gendrado existe em oposição ao outro gênero. A autora também afirma que o gênero é um discurso que fundamenta e cria a ideia de "natureza sexual", que é, então, estabelecida como anterior à cultura. Para Butler, portanto, não só o gênero é um conceito construído, como também o é a ideia de "natureza sexuada”. O estabelecimento desses conceitos como anistóricos e pré-sociais é responsável por garantir que os indivíduos consintam livremente em ser governados. 
A sociedade é construída por uma convenção social, mas também é responsável por construir a identidade dos indivíduos que são parte dela. Sendo assim, não se pode ter uma identidade totalmente desligada dessas relações de dominação, pois os corpos não só são entendidos e construídos a partir do princípio de visão social. As identidades presentes na sociedade, portanto, se constroem com base nas relações de dominação, que definem papéis de gênero de acordo com essas relações, designando como masculino tudo o que se relaciona com a posição superior ou "para cima", enquanto o feminino seria o inferior e o dominado. O próprio ato sexual e as divisões de trabalho entre os gêneros demonstram essas relações. ${ }^{2}$ Mesmo aqueles que fogem à regra e se desligam do modelo estabelecido - que afirma que só é mulher aquela que nasce com o sexo biológico feminino, como no caso dos indivíduos transexuais - são influenciados por uma sociedade que tem um conceito fixo do que é o feminino.

A participante desta pesquisa, que chamaremos de Renata, tem 33 anos, é graduada em Física e iniciou seu doutorado na área, mas também atua como fotógrafa. Ela foi contactada através de uma rede social, após ser indicada por um amigo. Mostrou-se muito receptiva e interessada desde o primeiro contato pela Internet, inclusive expondo opiniões sobre o tema, dando dicas e indicando eventos que pudessem contribuir para a pesquisa. O primeiro contato foi feito numa livraria na cidade do Rio de Janeiro, onde havia um café. Renata estava à vontade para contar sua história. As primeiras perguntas tiveram o objetivo de mostrar como a entrevistada se definia. Em primeiro lugar, Renata se define como mulher. Ao ser questionada sobre o que é ser transexual, afirmou que não gosta de dizer que é transexual, mas que está transexual, pois a sociedade a designa dessa forma, assim como pode designá-la de outra maneira em outro momento.

Logo no início da entrevista, Renata demonstrou que gosta de pensar além do óbvio, o que é fruto de todo o conhecimento que adquiriu em sua vida acadêmica e na busca por entender melhor sua condição. Ela conta que, quando decidiu assumir sua identidade para o mundo - pois havia tido uma convulsão devido ao estresse -, buscou em vários livros e trabalhos acadêmicos referências sobre a transexualidade. A partir de então, deu início à reconstrução de sua identidade, assumindo-se como mulher.

O fenômeno transexual foi descrito pela primeira vez por Harry Benjamin e batizado de "transexualismo". Para Benjamin citado por Arán, Zaidhaft e Murta, seria inadequada a determinação do sexo baseada em distinções anatômicas, já que não haveria distinção absoluta entre o masculino e o feminino. ${ }^{18}$ Essa categoria faria referência àqueles indivíduos que não se adequam fisicamente a seu gênero autopercebido, podendo ser operados ou não operados. $\mathrm{O}$ psicólogo John Money, citado por Cardoso, defendeu que o gênero seria construído por vivências culturais e se sobreporia ao sexo biológico. Ele decidiu, no entanto, utilizar a expressão "disforia de gênero" para caracterizar os indivíduos cujo gênero estaria em desacordo com o sexo biológico. Para Money, a patologia estaria inserida no órgão genital e não no gênero. Money também foi 
o responsável por criar o conceito de "identidade de gênero", muito utilizado atualmente para defender a diferenciação entre gênero e sexo biológico. A identidade de gênero seria a convicção do indivíduo a respeito do sexo ao qual acredita pertencer. ${ }^{15}$

Os estudos do psiquiatra e psicanalista Robert Stoller também foram importantes para a compreensão do tema. Stoller criou o conceito de "núcleo de identidade de gênero" e afirmou que a identidade masculina ou feminina é estabelecida no segundo ou terceiro ano da vida do indivíduo. ${ }^{7}$ No caso estudado, a entrevistada conta que a identificação com elementos ligados ao feminino ocorreu muito cedo em sua infância.

Ela considera que os primeiros elementos designados socialmente como femininos com os quais se identificou foram as vestimentas. Sua mãe e sua tia tinham uma sociedade de confecção de roupas e Renata conta que, por ser a primeira a ter nascido, se tornou modelo tanto das roupas femininas quanto masculinas dessa confecção. A partir daí, percebeu que preferia se vestir com as roupas femininas e pediu à mãe que pudesse vesti-las no dia a dia. Num primeiro momento, sua mãe concordou. Outros comportamentos ligados ao feminino estiveram presentes nas brincadeiras da entrevistada. Ela conta que ganhava muitos bonecos, mas que não brincava com eles da maneira como os meninos eram ensinados a brincar, de luta. Suas brincadeiras com os bonecos tinham o objetivo de cuidar deles como se fossem bebês. Renata diz que fazia isso, pois observava sua mãe cuidando do irmão recém-nascido e o cuidado que ela tinha com os outros. Ela também afirma ver a mãe como seu espelho. Essa identificação com a mãe foi designada por Stoller como um dos elementos essenciais para caracterizar uma mulher transexual. Outras características especificadas por Stoller são: a identificação sem ambiguidades com o sexo oposto e a relação de horror vivida com o pênis. Devido a essa experiência vivida com o órgão genital, o tratamento prescrito por Stoller era a cirurgia de transgenitalização, que consiste na conversão do órgão sexual para o sexo oposto. ${ }^{7}$

A entrevistada relata que viveu a experiência de horror com o órgão sexual e que sentia uma repulsa por esse órgão, o que a fazia ter vergonha de tomar banho em sua adolescência. Ela conta que só conseguiu "sobreviver" a essa experiência, que considerava um martírio, devido à atuação de uma psicóloga, que a convenceu que ela deveria cuidar de sua genitália, para que futuramente esta pudesse ser transformada:

Então, foi a única forma de eu conseguir reduzir esse repúdio ao órgão, à genitália, por saber que essa genitália podia ser usada futuramente para outras coisas, no caso, para ser convertida para a genitália feminina.

Renata afirma que só conseguiu se livrar do incômodo e da repulsa pelo órgão genital depois que fez a cirurgia de transgenitalização. Ou seja, a partir do momento em que se livrou daquele símbolo, que era a única coisa que a caracterizava como homem. A partir do momento em que 
ela não possuía mais o órgão, todas as outras características masculinas do seu corpo passaram a não incomodar mais. Ela justifica esse fato, dizendo que essas características também podem ser encontradas nas mulheres cisgênero, que são aquelas que nasceram com o órgão genital feminino. ${ }^{19}$ O órgão masculino, no entanto, não pode ser observado nas mulheres cisgênero e, por esse motivo, ele se tornou o símbolo daquilo que a descaracterizava como mulher. Seguindo essa lógica, a entrevistada teve que se submeter à cirurgia para eliminar aquilo que a descaracterizava como mulher e, por isso, causava repúdio. Mesmo dizendo que não fez outras cirurgias por ter medo de intervenções cirúrgicas, ela quis se submeter à cirurgia de transgenitalização, pois a presença do órgão genital masculino havia se tornado insuportável.

Percebe-se também, no relato apresentado, que Renata faz questão de se comparar com as mulheres cisgênero, sobretudo com a tia e, principalmente a mãe. Como foi visto anteriormente, a mãe é vista como seu espelho, como uma pessoa com a qual ela se identifica, principalmente nas características de comportamento, como o cuidado com os outros. Nessas comparações, a entrevistada reforça para si, e para a entrevistadora, que suas características físicas não podem descaracterizá-la como mulher, conforme é possível perceber no seguinte trecho:

Muita gente fala pra mim que eu tenho nariz grande, mas minha mãe tem gogó. Se gogó é de homem, então minha mãe é homem. então eu nasci de um homem. Mas, peraí, então homem não engravida? Então, assim, minha mãe tem gogó e eu não tenho. Minha mãe tem uma mão maior do que a minha. Minha mão é grande, mas minha mãe tem uma mão maior. Minha mãe calça mais do que eu. Minha mãe calça 40 e eu calço 37.

Esse exemplo também pode ser observado no seguinte trecho:

[...] de repente, o meu rosto é um pouco bruto. Mas existem tantas mulheres grandonas, que eu até olho pela roupa e eu acho: 'nossa, aquela mulher é tão grandona, tem tantos caracteres masculinos, e ela ainda é mulher'. E ela tá pouco se lixando pra esses caracteres, porque pra ela, é a natureza dela. Então, se é a natureza dela, se minha natureza é assim, será, entendeu?

De acordo com Bourdieu, enquanto os homens tendem a mostrar insatisfação com partes do corpo que consideram pequenas demais, as mulheres tendem a considerar menos femininas aquelas partes que parecem grandes demais. ${ }^{2}$ Essa observação fica evidente quando a entrevistada coloca em seu discurso que sua mãe tem mãos e pés maiores que os seus, com a finalidade de reforçar que sua feminilidade não pode ser questionada devido a suas características físicas. Também fica evidente quando ela diz que não se importa que seu rosto seja grande, pois existem muitas mulheres "grandonas", que ainda assim, são mulheres.

Através de trechos como os apresentados acima, pôde-se perceber que Renata criou mecanismos de defesa para lidar com seu corpo e com sua condição de mulher transexual. Esses mecanismos 
são observados quando ela se compara com as mulheres cisgênero, buscando mostrar que ela não é menos mulher devido a suas características físicas. Em alguns momentos, inclusive, ela busca mostrar que é mais feminina do que algumas mulheres cisgênero, sobretudo nas suas comparações com a mãe, ao afirmar que a mesma tem "gogó", o que seria uma característica masculina. No entanto, antes de criar esses mecanismos e de aceitar o seu corpo, ao longo do seu processo de construção de identidade, ela afirma que buscava adequar seu corpo àquilo que se esperava de uma mulher. Sendo assim, usava seios postiços, salto alto e outros acessórios que a fizessem parecer mais feminina de acordo com os padrões normativos impostos pela sociedade. Outro mecanismo de defesa utilizado pela entrevistada para aceitar sua condição de mulher transexual é o humor, o que pode ser percebido no seguinte trecho.

E muita gente pergunta às vezes na rua: "ah, você é homem ou você é mulher?". E aí normalmente eu respondo uma coisa bem absurda, eu falo: "ah, eu sou uma girafa", "eu sou um ornitorrinco". Às vezes eu falo que eu sou um unicórnio.

Ainda que seja uma brincadeira, uma resposta absurda com o objetivo de deixar o interlocutor sem ação, essa fala diz algo sobre a personalidade de Renata. Ao dizer que "ser também uma girafa é um processo de construção", ela expressa seu sentimento de liberdade de ser o que quiser, que foi conquistado após seu processo de construção da identidade feminina. Essa face da feminilidade já havia sido apontada por Birman, que afirma que ela é da ordem do indizível, por transcender a regulação fálica e, por esse motivo, implica singularidade e aventura. ${ }^{17}$

Para Renata, portanto, ser mulher se define por esse sentimento de liberdade de seguir os próprios desejos. O "ser mulher" também se define, para ela, como um processo de construção, que pode ser aplicado tanto a mulheres cisgênero, quando a transgênero. Tal concepção já havia sido formulada por Beauvoir, em sua obra $O$ segundo sexo: a experiência vivida, quando a autora afirma que "Ninguém nasce mulher, torna-se mulher". Segundo a autora:

Nenhum destino biológico, psíquico, econômico define a forma que a fêmea humana assume no seio da sociedade; é o conjunto da civilização que elabora esse produto intermediário entre o macho e o castrado que qualificam de feminino. ${ }^{20}$

\section{Sentimento de não-lugar}

O processo de construção de Renata envolveu várias etapas, e pode-se dizer que uma das mais importantes consistiu no processo que se encerrou com a realização da cirurgia de transgenitalização. Esta também é citada na entrevista como fundamental para a conquista da liberdade: 
[...] depois que eu acabei com esse problema da genitália eu ganhei uma coisa chamada liberdade. Depois que eu resolvi isso, as coisas ficaram mais simples. E todos os problemas que eu achava que tinha: "ah, não, mas eu tenho peito pequeno"; "ah, meu narizé feio". Tudo isso acabou. Porque aquela coisa que me incomodava acabou.

Para alguns psicanalistas, a cirurgia de transgenitalização não é recomendada no caso de transexuais, ${ }^{4}$ pelo fato de que a recusa não seria ao órgão propriamente dito, mas ao significante do gozo fálico. ${ }^{20}$ Essa ideia foi proposta por Jacques Lacan, citado por Vilela, que considerou que os transexuais deveriam ser entendidos como psicóticos, por seu sexo ter de ser inventado. De acordo com a definição de Freud para psicose, esta consistiria num conflito ocorrido entre o ego e o mundo externo, que seria fruto da frustração de um desejo causada pela realidade.

Sendo assim, a realidade se tornaria insuportável para o psicótico, fazendo com que ele deixasse de perceber o mundo exterior, ou não fosse afetado pelo mesmo. Para Lacan, o transexual recusa os ditos dos adultos que o caracterizaram como menino ou menina devido a sua disposição anatômica, invalidando seus discursos. ${ }^{21}$ Birman destaca que, de acordo com a teoria de Freud, a questão da diferenciação entre os sexos seria construída de acordo com a lógica da função fálica, de acordo com a presença ou a falta do falo. ${ }^{17}$ Desta forma, o transexual, ao recusar o discurso dos adultos e recusar diferenciação entre os sexos, estaria recusando a lógica da função fálica, o que o caracterizaria como psicótico. De acordo com os estudos de Lacan, a cirurgia de transgenitalização não resolveria o problema do incômodo causado pelo órgão genital, pois o que realmente incomoda é o fato de esse órgão ter sido o responsável pela sua significação como menino ou como menina.

No caso apresentado, no entanto, a cirurgia constituiu parte importante da construção da identidade feminina. Não foi possível, para Renata, aceitar seu corpo com um órgão genital masculino. Por esse motivo, ela é categorizada pela psiquiatria como transexual.

De acordo com a décima edição da Classificação Estatística Internacional de Doenças e Problemas Relacionados à Saúde (CID-10), ela se enquadraria na categoria de "transexualismo". ${ }^{5}$ Já no DSM (Manual Diagnóstico e Estatístico das Doenças Mentais) IV e V, ela se enquadraria, respectivamente, nas categorias de "transtorno de identidade de gênero" e "disforia de gênero".22,23 Segundo Benjamin, citado por Barbosa (p. 360), uma travesti, diferentemente do caso de Renata, não teria esse incômodo em relação ao seu órgão genital e, portanto, não teria interesse em fazer a cirurgia. Para o autor, seria essa, então, a diferença fundamental entre as duas categorias, travesti e transexual. ${ }^{24}$ Leite Junior, no entanto, afirma que as pessoas que normalmente são denominadas "travestis", no Brasil, que são aquelas que utilizam tratamentos hormonais e cirurgias, mas optam por não realizar a cirurgia de transgenitalização, são conhecidas em outros países como transexuais secundários, transexuais não indicados para cirurgia ou transexuais de identidade moderada. ${ }^{14}$ 
Renata destaca, em seu discurso, que não concorda que haja uma diferenciação tão acentuada entre travestis e transexuais. Na prática, pode-se perceber que há uma linha muito tênue entre as identidades ditas "trans" e que essas categorizações se perdem na medida em que os casos são analisados individualmente.

Percebe-se, portanto, que as áreas do conhecimento abordadas consideram a condição transexual da entrevistada como patológica. Canguilhem discute os conceitos de normal e patológico e define que os limites entre a normalidade e a patologia são imprecisos. Em muitos casos, o conceito de doença está associado àquilo que é visto como nocivo e indesejável pela sociedade. ${ }^{25}$ É justamente nesse lugar que se insere o sujeito transexual, pois ele se torna uma ameaça à ordem estabelecida que reforça a diferenciação entre os sexos. Para Canguilhem, o conceito de normal é equívoco na medida em que sofre alterações de acordo com os julgamentos de valor daquele que fala. $\mathrm{O}$ autor atribui à filosofia realista a ideia de que toda generalidade é indício de uma essência e poderia trazer a compreensão de uma verdade única e de um tipo ideal. O conceito de patológico, portanto, também pode ser considerado um equívoco, visto que pode sofrer mudanças de acordo com conceitos de valor. ${ }^{25}$

É importante destacar que a ideia de patologia mental relacionada aos comportamentos, sobretudo sexuais, que fogem a uma normatividade, começou a ser construída a partir do século XVIII. Foucault aborda a questão da sexualidade como um discurso e afirma que este, que antes era regulado pelos aparatos da lei, passou a ser regulado pela racionalidade, sobretudo pela medicina. Sendo assim, aquilo que era considerado "contra a lei" deu lugar a um "contra a natureza" ${ }^{26}$

É possível perceber, ainda hoje, a presença desse discurso citado por Foucault, pois é a ideia de "contra a natureza" que reforça a não aceitação dos sujeitos que não obedecem às normativas que regulam a sexualidade e as expressões de gênero. A vivência de uma identidade de gênero que difere daquela estabelecida a partir do sexo biológico não constitui, nos países ocidentais, um crime perante a lei, mas o é perante a sociedade. Os sujeitos que fogem à normativa se tornam marginalizados, devido a uma rejeição que se baseia na racionalidade e na "natureza".

Foucault também chama atenção para o fato de que, durante muito tempo, os hermafroditas, que são sujeitos que nascem com um sexo anatômico ambíguo, foram vistos como criminosos. ${ }^{26}$ Hoje esses sujeitos, assim como os transexuais, são vistos como doentes. No caso dos hermafroditas, a doença está presente na anatomia, enquanto na transexualidade, conforme descrito pela psiquiatria, a doença se localiza na mente. Sendo assim, nos discursos da contemporaneidade, pode-se dizer que a patologia se localiza nos pontos específicos que contrariam a normativa da diferença entre os sexos.

Alguns movimentos sociais têm surgido com o objetivo de obter a despatologização das identidades "trans". O movimento "Stop Trans Pathologization", que conta com a participação de profissionais e ativistas "trans", surgiu com esse objetivo. Um texto disponível na página do 
movimento na internet traz à tona a ideia de que a psiquiatria cometeu um erro ao classificar a transexualidade como doença. O texto defende que a patologia estaria inscrita na própria sociedade, que, ao não aceitar aqueles que não se adequam ao binarismo de gênero, cometem uma violência simbólica, trazendo sofrimento a esses indivíduos. ${ }^{6}$

A entrevistada não aceita essa perspectiva de patologização de sua condição, nem as nomenclaturas utilizadas pela medicina e, por isso, prefere se definir como "mulher transgênero". De acordo com ela, a palavra "transgênero" seria a mais adequada para se definir, pois se refere diretamente a uma transformação que ocorre no gênero, enquanto a palavra "transexual" estaria se referindo à sexualidade. Renata destaca a diferença entre identidade de gênero e sexualidade.

Menezes $^{25}$ afirma que não pode haver relação direta entre a identidade de gênero e a orientação sexual. Dessa forma, pode-se encontrar vários tipos de identidade de gênero nas categorias homossexuais e heterossexuais. ${ }^{27}$ A entrevistada afirma que sempre se viu como bissexual, tanto antes, quanto depois da cirurgia. Por não aceitar a nomenclatura utilizada pela psiquiatria, Renata solicitou que o médico responsável por fazer o laudo que a tornava apta à cirurgia de transgenitalização, utilizasse a palavra "transgeneridade". Ela conta que o médico aceitou, mas o laudo demorou mais tempo para ficar pronto. A necessidade do laudo do médico se justifica pelo fato de que no Brasil, o sujeito transexual tem que passar por um acompanhamento de, no mínimo, dois anos com um psiquiatra, para que seja comprovado o diagnóstico de "transexualismo" e o processo transexualizador seja iniciado. ${ }^{28}$

Essa perspectiva da patologização da transexualidade, embora facilite que o tratamento seja oferecido em hospitais públicos, de acordo com Butler, demonstra uma estrutura paternalista do estado em detrimento da autonomia da pessoa de decidir o que fazer com o próprio corpo. Butler também destaca que a patologização pode se tornar um instrumento nas mãos dos "transfóbicos", que são aqueles que não aceitam a vivência da transexualidade. ${ }^{4}$ A patologização se torna justificativa para uma não aceitação desses sujeitos na sociedade. Nessa perspectiva, se os transexuais são doentes, deve-se buscar a cura, e não uma mudança na sociedade para que esses indivíduos sejam reconhecidos como cidadãos como quaisquer outros.

Para Lima, os sujeitos só se tornam inteligíveis na sociedade quando são identificados por um gênero, que é responsável por regular e padronizar comportamentos. De acordo com a normalização binária, o gênero deveria estar de acordo com o sexo biológico. No entanto, a lógica binária não é capaz de capturar todos os corpos que produz, designando, assim, os que não se encaixam, como seres abjetos. As categorizações criadas para esses seres abjetos, sobretudo pela psiquiatria, seriam, portanto, resultado de um processo que tem como característica "ajustar" os indivíduos desviantes, com o objetivo de proteger a sociedade dessas expressões. ${ }^{9}$ Portanto, a patologização da transexualidade, não importando qual a nomenclatura utilizada, favorece a lógica da normalização binária, segundo a qual o gênero é definido pelo sexo biológico. 
Essa lógica da normalização binária, no entanto, está presente no discurso de Renata, na medida em que considerou fundamental que seu órgão genital fosse transformado, para que não só fosse reconhecida, como pudesse se reconhecer como mulher. O sofrimento causado pela presença do órgão está ligado ao sofrimento causado por sua não aceitação perante a sociedade, que ocorreu desde sua infância, quando não conseguia se relacionar com as outras crianças da sua idade. Ela afirma que não se relacionava porque tinha muito medo, já que costumava ser agredida pelos meninos. Além disso, houve uma não aceitação dentro de sua casa, visto que os pais não entendiam e não aceitavam seu comportamento feminino, e utilizavam a violência para corrigi-la. Este trecho da entrevista demonstra de que maneira Renata se via quando criança: "Então é o seguinte, eu me via como uma menina que brincava, que usava roupa, que brincava, usava batom, tudo".

No entanto, as situações de violência vividas, junto à consequente dificuldade de ter sua identidade reconhecida, fizeram com que Renata se fechasse num mundo imaginário e não se relacionasse com as outras pessoas. Como relata, em seu mundo imaginário, podia ser quem realmente era. Ela se lembra que, em muitos momentos, ouviu as pessoas ao seu redor dizerem que a Renata era doente mental, enquanto fazia vários exames, como eletroencefalograma, com o objetivo de diagnosticá-la. Renata também conta que passou por um tratamento psicológico na escola onde estudava, com o objetivo de corrigir seu comportamento. Conta que, na época, foi convencida pela psicóloga de que seus sentimentos com relação a sua identidade eram errados.

O processo de construção da identidade de Renata foi, então, doloroso e muito controverso. A mesma afirma que, embora hoje possa se reconhecer como mulher sem controvérsias, seu processo de construção é contínuo.

Pode-se dizer que, nesse processo doloroso de construção de identidade, a entrevistada passou por várias transformações com o objetivo de localizar seu lugar na sociedade. Desde a infância, se viu presa num lugar, o qual nem ela, nem as pessoas com quem conviveu compreendiam. Conforme foi dito por Lima, os sujeitos só são reconhecidos a partir de seu gênero. ${ }^{9}$ Renata, por não se encaixar em nenhum dos dois gêneros quando criança, não tinha um lugar social. Por esse motivo, houve uma cobrança por parte dos pais e de outras pessoas do seu convívio, para que obedecesse às normas que caracterizam o gênero masculino, pois entende-se na sociedade que o gênero está diretamente ligado ao sexo biológico. Supõe-se também que um indivíduo não pode possuir dois sexos, ainda que exista a possibilidade de se apresentar um sexo anatomicamente ambíguo. Essas concepções parecem óbvias para qualquer pessoa que aborde o tema, mas na verdade, são conceitos arbitrários que foram eternizados pelos rituais presentes nas diversas culturas. Esses rituais têm como objetivo educar os sujeitos para que eles sejam moldados de acordo com os padrões já estabelecidos, tornando-se, eles próprios, evidências desses conceitos eternizados, formados a partir das relações de dominação. ${ }^{2}$ 
Como consequência da dificuldade de encontrar seu lugar social durante a infância, Renata foi em busca de seu lugar como mulher quando adulta, através da externalização de uma aparência cada vez mais feminina, bela e sensual, pois acreditava que a feminilidade se localizava nesses caracteres. É possível que a própria cirurgia de transgenitalização, nesse caso, também esteja ligada a um esforço pela adaptação ao que se entende por feminino. Podemos dizer que o ódio ao órgão genital se traduza pela repulsa àquilo que se tornou um símbolo do sofrimento de uma vida. Teria então o órgão sexual se tornado o significante de seu não-lugar social?

\section{Considerações finais}

A pesquisa apresentada teve como objetivo questionar os olhares sobre um tema tão pouco aprofundado como a transexualidade. Percebe-se que a sociedade ainda não está preparada para romper com certos conceitos preestabelecidos que nada têm de naturais. Questionar a diferenciação entre os sexos se torna fundamental no estudo deste tema e traz à tona uma série de outros questionamentos não necessariamente ligados ao universo "trans", como as relações de poder que acabam legitimando certas violências, ainda que simbólicas, a grupos que decidem não obedecer às regras impostas por essas relações. Ao mesmo tempo, tais questionamentos se tornam uma ameaça à ordem estabelecida, pois envolvem conceitos naturalizados e enraizados na cultura.

Torna-se também fundamental ampliar os estudos científicos relacionados às identidades "trans", visto que as teorias abordadas ainda não conseguem capturar a pluralidade de corpos que são produzidos. Esses corpos são, hoje, categorizados e descaracterizados, gerando uma série de confusões. As categorizações têm como objetivo padronizar esses corpos diferenciados, entendendoos como seres abjetos e que devem ser tratados como doentes, pois sua própria existência questiona um dos pilares da sociedade: a diferenciação entre os sexos.

Algumas limitações foram notórias no estudo realizado, como a diferenciação extrema entre algumas categorias trans. Devido a esse fato, alguns sujeitos abordados não se tornaram aptos para a realização da pesquisa, embora correspondessem a vários critérios determinados, devido ao não interesse pela cirurgia de transgenitalização. Essa diferenciação, sobretudo entre travestis e transexuais, foi um dos fatos que limitaram a realização deste estudo. Percebe-se que, na prática, a linha que separa essas duas categorias se perde.

Torna-se necessário, no entanto, que essas categorias sejam abordadas de forma individual em futuras pesquisas, para que possam ser desmistificadas e para que seja trazido um novo olhar a esses sujeitos, que se tornam marginalizados justamente devido à ampla aceitação de discursos científicos que os descaracterizam. Um ponto importante que poderia ser abordado seria a diferença entre a representação do órgão sexual masculino no discurso das mulheres trans que 
optam por fazer a cirurgia de transgenitalização e das que não têm interesse na mesma. A opção pela cirurgia não é um fator isolado, mas reflete o sentimento que o transexual tem em relação ao seu próprio corpo. É possível, portanto, que a análise dos discursos dessas duas formas de transexualidade nos traga mais pistas sobre o significante que faz com que o órgão seja rejeitado ou não pelo sujeito. Torna-se também importante abordar a questão dos homens transexuais, que são ainda mais esquecidos do que as mulheres. Esses homens são, inúmeras vezes, vistos como lésbicas masculinizadas e não como transexuais.

É essencial que a psicologia apresente olhares diferenciados a todos os sujeitos. No caso dos transexuais, o esforço deve ser redobrado, para que o profissional não reproduza os discursos padronizados existentes e possa escutar aquele que se encontra à sua frente. Tanto o profissional quanto o pesquisador da área da psicologia deve ir além do óbvio em suas reflexões, visto que se trata de um saber que não se fecha, mas está em constante construção. Perder-se em teorias já estabelecidas é um risco que se corre, mas que deve ser evitado. A teoria deve, portanto, ser utilizada como base para o trabalho do psicólogo, mas não se sobrepor ao discurso daquele que se apresenta. Sendo assim, a discussão proposta neste trabalho se torna um importante passo para a ampliação dos olhares dos profissionais a esses sujeitos.

Percebe-se que há muito mais a ser discutido do que era esperado ao início desta pesquisa. Os sujeitos transexuais, por serem ainda uma minoria marginalizada, se tornam alvo de várias violências por não terem suas identidades reconhecidas em alguns espaços. A discussão sobre o assunto no meio científico torna-se fundamental para que esses sujeitos possam existir e ser reconhecidos, não mais como desviantes, mas apenas como cidadãos comuns.

\section{Referências}

1. De Beauvoir S. O segundo sexo: fatos e mitos. $4^{\text {a }}$ ed. São Paulo: Difusão Européia do Livro; 1970.

2. Bourdieu P. A dominação masculina. Rio de Janeiro: Bertrand Brasil; 1999.

3. Butler J. Sujeitos do sexo/gênero/desejo. In: Butler J. Problemas de gênero: feminismo e subversão da identidade. Rio de Janeiro: Civilização Brasileira; 2003. p. 17-60.

4. Butler J, Rios J. Desdiagnosticando o gênero. Physis 2009; 19(1):95-126.

5. Organização Mundial da Saúde. Classificação dos transtornos mentais e de comportamento da CID10. Porto Alegre: Artes Médicas; 1993.

6. Manifesto. Rede Internacional Pela Despatologização Trans. Stop Trans Pathologization [Internet]. 2012. [acesso em: 8 ago. 2016]. Disponível em: http://www.stp2012.info/old/pt/manifesto 
7. Arán M. A transexualidade e a gramática normativa do sistema sexo-gênero. Ágora (Rio J.) 2006; IX(1):49-63.

8. Perelson S. Transexualismo: uma questão do nosso tempo e para o nosso tempo. Rev. EPOS 2011; 2(2):1-19.

9. Lima F. Corpos, gêneros, sexualidades: políticas de subjetivação. $2^{\mathrm{a}}$ ed. Porto Alegre: Rede Unida; 2014.

10. Angelo V. Visibilidade trans: o fim do não lugar (parte 1). Folha de S. Paulo [Internet]. 01 fev. 2013. [acesso em: 8 ago. 2016]. Disponível em: http://blogay.blogfolha.uol.com.br/2013/02/01/visibilidadetrans-o-fim-do-nao-lugar-parte-1/

11. Godoy AS. Pesquisa qualitativa: tipos fundamentais. Rev. Adm. Empres. 1995; 35(3):20-29.

12. Duarte R. Pesquisa qualitativa: reflexões sobre o trabalho de campo. Cad. Pesquisa 2002; (115):139-154.

13. Freire EC, Araujo FCA, Souza AC, Marques D. A clínica em movimento na saúde de TTT's: caminho para materialização do sus entre travestis, transsexuais e transgêneros. Saúde Debate 2013; 37(98):477-484.

14. Leite Junior J. Nossos corpos também mudam: sexo, gênero e a invenção das categorias "travesti" e "transexual" no discurso científico [Tese]. São Paulo: Pontífica Universidade Católica de São Paulo; 2008.

15. Cardoso FL. Inversões do papel de gênero: “drag queens”, travestismo e transexualismo. Psicol. Reflex. Crit. 2005; 18(3):421-430.

16. 16., Rocha D, Deusdará B. Análise de conteúdo e análise do discurso: aproximações e afastamentos na (re)construção de uma trajetória. Alea: Estudos Neolatinos 2005; 7(2):305-322.

17. Birman J. Cartografias do feminino. São Paulo: Ed. 34; 1999.

18. Arán M, Zaidhaft S, Murta D. Transexualidade: corpo, subjetividade e saúde coletiva. Psicol. Soc. 2008; 20(1):70-79.

19. Jesus JG. Orientações sobre identidade de gênero, conceitos e termos [Internet]. $2^{a}$ ed. Brasília: Fundação Biblioteca Nacional; 2012 [acesso em: 8 jan. 2016]. Disponível em: https://pt.scribd.com/doc/239946489/ Orientacoes-Sobre-Identidade-de-Genero-Conceitos-e-Termos-Jaqueline-Gomes-de-Jesus

20. De Beauvoir S. O segundo sexo II: a experiência vivida. $2^{a}$ ed. São Paulo: Difusão Européia do Livro; 1967.

21. Vilela Y. O erro comum e a paixão transexual. Almanaque Online: Revista eletrônica do Instituto de psicanálise e saúde mental de Minas Gerais [Internet]. 2012; (11):1-11. [acesso em: 9 ago. 2016]. Disponível em: http://almanaquepsicanalise.com.br/wp-content/uploads/2015/09/ Incurs $\% \mathrm{C} 3 \%$ B5es-O-erro-comum-e-a-paix $\%$ C3\%A3o-transexual-Yolanda-Vilela.pdf

22. American Psychiatric Association. Diagnostic and statistical manual of mental disorders: DSM-IV. $4^{\mathrm{a}}$ ed. Washington: American Psychiatric Association; 1994.

23. American Psychiatric Association. Manual diagnóstico e estatístico de transtornos mentais: DSM-V. $5^{\mathrm{a}}$ ed. Porto Alegre: Artmed; 2014. 
24. Barbosa BC. "Doidas e putas": usos das categorias travesti e transexual. Sex. Salud Soc. 2013; (14):352-379.

25. Canguilhem G. O Normal e o patológico. $6^{a}$ ed. Rio de Janeiro: Forense Universitária; 2009.

26. Foucault M. História da sexualidade: a vontade de saber. Rio de Janeiro: Paz e Terra; 2014.

27. Menezes AB, Brito RCS, Henriques AL. Relação entre gênero e orientação sexual a partir da perspectiva evolucionista. Psic.: Teor. e Pesq. 2010; 26(2):245-252.

28. Brasil. Resolução no. 1.955, de 12 de agosto de 2010. Cirurgia de Transgenitalismo. Diário Oficial da União 03 set. 2010; Seção 1:109-110.

Recebido: $11 / 4 / 2016$

Revisado: 04/8/2016

Aceito: 17/8/2016 